\title{
Clinical and epidemiological characteristics of severe community-acquired pneumonia in children after introduction of the 10-valent pneumococcal vaccine
}

\author{
This article was published in the following Dove Press journal: \\ Pediatric Health, Medicine and Therapeutics \\ 24 August 2015 \\ Number of times this article has been viewed
}

\author{
Eduardo JF Lima ${ }^{1,2}$ \\ Maria JG Mello',2 \\ Maria FPM Albuquerque ${ }^{3}$ \\ Maria IL Lopes ${ }^{4}$ \\ George HC Serra ${ }^{2}$ \\ Maria AZ Abreu-Lima ${ }^{2}$ \\ Jailson B Correia' \\ Instituto de Medicina Integral \\ Prof. Fernando Figueira - IMIP \\ Recife; ${ }^{2}$ Faculdade, Pernambucana \\ de Saúde - FPS Recife; ${ }^{3}$ Centro de \\ Pesquisas Aggeu Magalhães, FIOCRUZ; \\ ${ }^{4}$ Hospital das Clínicas, Universidade \\ Federal de Pernambuco - UFPE, \\ Recife, Pernambuco, Brazil
}

\begin{abstract}
Background: Pneumonia is an important cause of morbimortality in Brazil, despite the extensive vaccination coverage and the socioeconomic improvement in the past years.

Objective: To describe the epidemiological and clinical characteristics of severe communityacquired pneumonia in children after the introduction of the 10 -valent pneumococcal conjugate vaccine (PCV10).
\end{abstract}

Methods: A prospective study included children $<5$ years old hospitalized for pneumonia between October 2010 and September 2013 in a tertiary hospital. Newborns and children with comorbidities were excluded. Pneumonia classification followed the clinical and radiological criteria established by World Health Organization (WHO). Clinical history, nutritional status, immunizations, diagnosis, disease course, and prognosis were analyzed.

Results: Among 452 children, almost $70 \%$ were $<2$ years, with no sex differences, and 10\% had weight-for-age $\mathrm{z}$ score below than -2.0 . Family income was up to one minimum wage in half the households, and $40 \%$ of mothers had completed high school. The suitability of both influenza and PCV10 vaccine schedules was $\sim 50 \%$. The first medical care happened later than 72 hours after the onset of symptoms in $42 \%$ of cases. Pneumonia was classified as severe or very severe in $83.9 \%$ of patients and for $23 \%$ as complicated. Global mortality was $1.5 \%$. Hypoxia, diagnosed in $51.5 \%$ of children, looked like a better prognosis predictor than the WHO classification.

Conclusion: New strategies for health care are necessary, such as the incorporation of peripheral saturometry as the "fifth signal", investment in vaccine coverage, and the adequacy of hospital infrastructure for assistance of severely affected patients.

Keywords: respiratory tract infections, pneumonia, child, pneumococcal conjugate vaccine, descriptive epidemiology

\section{Introduction}

Community-acquired pneumonia (CAP) remains a challenging public health problem despite the incorporation of novel vaccines and recommendations for disease management from the scientific community. ${ }^{1}$ Every year, $\sim 156$ million new cases of pneumonia occur worldwide in children $<5$ years of age, and the mortality rates are higher than $10 \%$ in developing countries. ${ }^{2}$ In 2011 , CAP accounted for $>1$ million deaths among children worldwide. ${ }^{3}$ Brazil is among the 15 countries with the highest incidence of pneumonia, and this disease is the leading cause of death among children aged 1-4 years. ${ }^{2}$ The introduction of the 10 -valent pneumococcal conjugate vaccine (PCV10) in Brazil in 2010 and the epidemiological transition resulting from improved
Correspondence: Eduardo JF Lima Avenida 17 de Agosto, 742 - apto 240 I - Casa Forte, Recife, Pernambuco, 52060-590, Brazil

Tel +55 8I 999624965

Email eduardojorge@imip.org.br 
socioeconomic conditions may have promoted changes in the clinical and epidemiological characteristics of severe pneumonia in children between the age of 1 month and 5 years. The implementation of the Unified Heath System improved the primary access and allowed a universal coverage of vaccination. ${ }^{4}$

In the fight against high infant morbidity and mortality, in addition to vaccination, it is necessary to correctly identify patients with pneumonia and provide appropriate treatment according to established protocols. ${ }^{5}$ Clinical diagnosis of pneumonia in children is a challenge because there is no clinically acceptable gold standard method; clinical and radiological evaluation is the most commonly used diagnostic criteria in daily practice. ${ }^{6}$ The World Health Organization (WHO) recommends giving more weightage to complaints of coughing and increased respiratory rate as indicators of pneumonia in children $<5$ years of age. ${ }^{7}$ Despite its limitations, chest radiography is the most useful diagnostic tool and is indicated in cases where hospitalization is necessary and complications are suspected. ${ }^{8}$ Measurement of peripheral oxygen saturation $\left(\mathrm{SpO}_{2}\right)$ should be used to evaluate the severity of pneumonia because it allows early identification of hypoxia and enables appropriate oxygen consumption., ${ }^{8,9}$ Other tests, such as blood count, erythrocyte sedimentation rate, $\mathrm{C}$-reactive protein, and procalcitonin, are not routinely used because of their low specificity in differential diagnosis of bacterial and viral pneumonia. ${ }^{6,10}$

In Brazil, vaccination against type B Haemophilus influenzae has been part of the immunization schedule since 1999. It rapidly led to a significant decrease in the number of cases of meningitis associated with type B H. influenzae. ${ }^{11}$ In mid-2010, PCV10 was implemented with great expectations for its impact on the prevalence of pneumonia and invasive diseases. ${ }^{12}$ More recently in 2014 , vaccination coverage against influenza offered to children between the age of 6 months and 2 years was extended to children $<5$ years of age. ${ }^{13}$

The recent introduction of novel vaccines through the National Immunization Program and the improvement in the health care system in Brazil over the past years may have altered the clinical course of pneumonia in children $<5$ years of age. ${ }^{4}$ This study aimed to describe the clinical and epidemiological characteristics of pneumonia in children after the introduction of PCV10.

\section{Methods}

This prospective and descriptive study was conducted between October 2010 and September 2013. Children $<5$ years of age hospitalized with a diagnosis of CAP were consecutively included in this study. The study was conducted in the Professor Fernando Figueira Institute of Integral Medicine (IMIP), which is a teaching hospital that exclusively assists users of the Unified Health System, Recife, Pernambuco, Northeastern Brazil. In IMIP, according to data obtained from DATASUS for the year $2012, \sim 30 \%$ of children $<5$ years of age, were hospitalized due to pneumonia.

The patients were admitted to the pediatric emergency care unit, hospital wards, and pediatric intensive care unit (ICU) of the institution. The study included children from 1 month to 59 months of age with diagnosis of pneumonia for whom a vaccination card was available. Children were excluded if they had any concomitant primary disease such as heart, liver, or kidney disease, chronic lung disease, neuropathy, hemoglobinopathies, congenital lung malformation, or a known diagnosis of immunodeficiency.

Diagnosis of pneumonia was based on the clinical and radiological criteria established by WHO, including the classification of severity. ${ }^{5}$ The WHO criteria for nonsevere pneumonia included a history of cough and/or difficult breathing of $<3$ weeks duration, with 1 ) increased respiratory rate (rate $\geq 60$ / minute if age $<2$ months, $\geq 50 /$ minute if age $2-11$ months, and $\geq 40 /$ minute if age 12-59 months); 2) lower chest wall indrawing (severe pneumonia); or 3 ) cyanosis and/or inability to feed or drink (very severe pneumonia). ${ }^{5}$ Imaging results were independently analyzed by two radiologists, following the WHO standard for epidemiological studies of vaccination effectiveness. ${ }^{14}$ In our study, in addition to alveolar condensation/infiltrate and pleural effusion, interstitial infiltrate was also considered as a radiological diagnosis of pneumonia. ${ }^{15}$

Complicated pneumonia was considered to include the presence of pleural effusion requiring drainage and the presence of pneumatoceles, pneumothorax, necrotizing pneumonia, or the association of pneumonia with sepsis. ${ }^{5,16}$

Diagnosis of hypoxic pneumonia was considered when $\mathrm{SpO}_{2}$ was $<92 \%$ and/or the attending physician recommended oxygen therapy. ${ }^{16}$

The variables were classified into three groups: family sociodemographic data (income, health conditions in the home, household crowding, and smoking in the home), maternal data (age, education, smoking history, and working outside the home), and child data (sex, age, nutritional status, birth weight, preterm birth, previous hospitalization, number of siblings, day care attendance, and adherence to vaccination schedule). The definitions for the main variables and optimal vaccination schedules in relation to PCV10, influenza, and rubella (MMR) are described in Table 1. For 
Table I Definition of the variables evaluated in children hospitalized due to pneumonia

\begin{tabular}{|c|c|}
\hline \multirow[t]{2}{*}{ Maternal education } & Incomplete secondary education ( $<$ II years) \\
\hline & Completed high school ( $\geq$ II years) \\
\hline Household crowding & Presence of two or more people sleeping in the same room as the patient \\
\hline Basic sanitation & $\begin{array}{l}\text { Drainage of the bathroom or toilet used by the residents is rated according to the presence or } \\
\text { absence of a sewage system or septic tank }\end{array}$ \\
\hline Maternal age & Rated according to $\mathrm{WHO}$ classification of adolescence: $<19$ years and $\geq 19$ years \\
\hline Smoking in residence and maternal smoking & $\begin{array}{l}\text { Presence or absence of smoking by residents and the presence or absence of smoking by the } \\
\text { mother }\end{array}$ \\
\hline Family monthly income & $\begin{array}{l}\text { The total amount of money received by residents, classified as } \leq I \text { minimum wage and } \\
>I \text { minimum wage }\end{array}$ \\
\hline I0-valent pneumococcal vaccine conjugate & $\begin{array}{l}\text { Considered adequately vaccinated when children received at least two vaccine doses in the first } \\
\text { year of life or one dose after the first year of life, as registered in the vaccination card }{ }^{20-24,30}\end{array}$ \\
\hline Influenza vaccine & $\begin{array}{l}\text { Considered adequately vaccinated when children were those who received (as registered in the } \\
\text { vaccination card) I) at least one dose of vaccine, as long as they had been previously immunized } \\
\text { with two doses at the first vaccination; 2) two doses in the case of primary vaccination. } \\
\text { Unvaccinated children were those }<6 \text { months or }>6 \text { months of age who did not use the } \\
\text { vaccine as described }\end{array}$ \\
\hline Triple viral vaccine or MMR & $\begin{array}{l}\text { Considered adequately vaccinated when children were those older than } 12 \text { months of age who, } \\
\text { according to the vaccination card, received at least one dose of vaccine }\end{array}$ \\
\hline Low birth weight & $\begin{array}{l}\text { Continuous numeric variable (expressed in g) obtained from the vaccination card, live birth } \\
\text { declaration, medical records, or reported by the mother: low birth weight }(<2,500 \mathrm{~g}) \text { or } \\
\text { adequate birth weight }(>2,500 \mathrm{~g})\end{array}$ \\
\hline Preterm birth & Gestational age $<37$ weeks as reported by the parent and/or partner \\
\hline Breast feeding & $\begin{array}{l}\text { Parent or partner was asked how long exclusive breastfeeding was maintained, and the variable } \\
\text { was transformed into dichotomous ordinal numbers }\end{array}$ \\
\hline Previous hospitalization & Parent or partner was asked if the patient had previously been hospitalized for any reason \\
\hline Nutritional status & $\begin{array}{l}\text { Evaluated according to WHO child growth standard }{ }^{25} \text { obtained from the calculation of z-scores. } \\
\text { According to the cut-off }<-2 \text {, the weight-for-age was divided into two categories: low/very low } \\
\text { and adequate. }\end{array}$ \\
\hline
\end{tabular}

Abbreviation: WHO, World Health Organisation.

nutritional assessment, we used the weight-for-age indicator because it is the rate most commonly used in epidemiological studies. Data related to the period between the onset of symptoms and first medical consultation, symptoms and signs present at the time of admission, treatment provided, transfer to the ICU, and clinical status after hospitalization (discharge or death) were obtained.

Data were organized and analyzed using the Statistical Package for Social Sciences (SPSS) software version 21.0 and StatCalc software version 7.1.0.3. The variables in nominal or ordinal scale were expressed as frequency distributions, whereas the length of hospitalization was summarized as the median and interquartile range. For contingency analysis, the chi-square test or Fisher's exact test was used, assuming a significance level of 0.05 to reject the null hypothesis.

We compared the frequency distribution of pneumonia classified according to disease severity by $\mathrm{WHO}$, and the frequency of complicated and hypoxic pneumonia was evaluated according to age, period of first medical consultation, pleural effusion, transfer to the ICU, length of hospitalization, and clinical status after hospitalization (discharge or death).
This study was submitted to and approved by the IMIP Research Ethics Committee under Process No 1860 and registered under CAAE No 0128.0.099.000-10. All parents or legally accepted guardians had signed an informed consent form.

\section{Results}

After completing the eligibility criteria, 452 consecutive cases of patients hospitalized due to pneumonia were analyzed. Table 2 presents the distribution of family and maternal demographic characteristics as well as the medical histories and clinical data of the children. Approximately $70 \%$ of the children were $<2$ years of age and $10 \%$ showed a weightfor-age of $<-2 \mathrm{z}$. The monthly income was $\leq 1$ minimum wage in $50 \%$ of the families, and household crowding was observed in $26.1 \%$ of the households. In relation to the clinical data of the children, it was notable that vaccine adherence for PCV10 was $50.4 \%$.

Some of the clinical characteristics such as classification of pneumonia and frequency of complicated and hypoxic pneumonia are presented in Table 3. 
Table 2 Frequency distribution of family/maternal demographic characteristics and clinical data/medical history of 452 children hospitalized due to community-acquired pneumonia at IMIP, Recife, Pernambuco, Brazil, between October 2010 and September 2013

\begin{tabular}{|c|c|c|}
\hline & $\mathbf{N}$ & $\%$ \\
\hline \multicolumn{3}{|l|}{ Clinical data and medical history } \\
\hline Male & 234 & 51.8 \\
\hline \multicolumn{3}{|l|}{ Age (months) } \\
\hline$<6$ & 121 & 26.8 \\
\hline $6-12$ & 66 & 14.6 \\
\hline $13-24$ & 127 & 28.1 \\
\hline$>24$ & 138 & 30.5 \\
\hline \multicolumn{3}{|l|}{ Nutritional weight-for-age status } \\
\hline Adequate weight $(z>-2)$ & 407 & 90.0 \\
\hline Low/very low weight ( $z \leq-2$ ) & 45 & 10.0 \\
\hline Low birth weight & 47 & 11.3 \\
\hline Preterm birth & 36 & 8.5 \\
\hline Previous hospitalization & 88 & 18.7 \\
\hline Day care attendance & 14 & 3.0 \\
\hline \multicolumn{3}{|l|}{ Family composition } \\
\hline No siblings & 196 & 43.4 \\
\hline Siblings present & 256 & 56.6 \\
\hline I sibling & 137 & 30.3 \\
\hline$\geq 2$ siblings & 119 & 26.3 \\
\hline \multicolumn{3}{|c|}{ Compliance with I0-valent pneumococcal vaccine schedule } \\
\hline Adequate & 228 & 50.4 \\
\hline Inadequate & 224 & 49.6 \\
\hline \multicolumn{3}{|c|}{ Compliance with Influenza vaccination schedule } \\
\hline Adequate & 190 & 42.0 \\
\hline Inadequate & 262 & 58.0 \\
\hline \multicolumn{3}{|c|}{ Compliance with triple viral vaccine schedule } \\
\hline Adequate & 231 & 51.1 \\
\hline Inadequate & 221 & 48.9 \\
\hline \multicolumn{3}{|c|}{ Family/maternal demographic characteristics } \\
\hline \multicolumn{3}{|l|}{ Family income } \\
\hline$\leq \mathrm{I}$ minimum wage & 224 & 49.5 \\
\hline$>I$ minimum wage & 177 & 39.2 \\
\hline No Information & 51 & 11.3 \\
\hline \multicolumn{3}{|l|}{ Water supply } \\
\hline Yes, but without plumbing & 12 & 2.7 \\
\hline Indoor plumbing & 433 & 95.8 \\
\hline No water supply & 6 & 1.3 \\
\hline No Information & I & 0.2 \\
\hline \multicolumn{3}{|l|}{ Sanitation } \\
\hline Yes, sewage collection network & 7 & 1.5 \\
\hline Yes, septic tank & 424 & 93.8 \\
\hline Yes, other types & 4 & 0.9 \\
\hline No & 14 & 3.1 \\
\hline No Information & 3 & 0.7 \\
\hline \multicolumn{3}{|l|}{ Household crowding } \\
\hline Yes & 118 & 26.1 \\
\hline No & 322 & 71.2 \\
\hline No Information & 12 & 26.1 \\
\hline Maternal age $<19$ years & 42 & 9.4 \\
\hline \multicolumn{3}{|l|}{ Maternal education } \\
\hline$<$ II years of schooling & 270 & 61.6 \\
\hline
\end{tabular}


Table 2 (Continued)

\begin{tabular}{lll}
\hline & $\mathbf{N}$ & $\%$ \\
\hline Mother works outside the home & & 26.3 \\
Yes & 119 & 72.8 \\
No & 329 & 0.9 \\
No Information & 4 & 30.1 \\
Smoking in residence & 140 & 23.6 \\
$\leq 20$ cigarettes/day & 47 & 76.4 \\
$>20$ cigarettes/day & 93 & 8.4 \\
Maternal current smoker & 38 & \\
\hline
\end{tabular}

With regard to clinical complications, pleural effusion assessed via chest radiography was present in 145 (32.1\%) patients, $88(60.7 \%)$ of whom underwent pleural puncture and $83(57.3 \%)$ underwent closed thoracic drainage. There were $17(3.8 \%)$ transfers to the ICU and seven (1.5\%) deaths. The median hospital stay was 5 days with an interquartile

Table 3 Frequency distribution of diagnostic and respiratory care data of 452 children hospitalized due to community-acquired pneumonia at IMIP, Recife, Pernambuco, Brazil, between October 2010 and September 2013

\begin{tabular}{|c|c|c|}
\hline $\begin{array}{l}\text { Variables related to the diagnosis and } \\
\text { respiratory care }\end{array}$ & $\mathbf{N}$ & $\%$ \\
\hline \multicolumn{3}{|l|}{ WHO pneumonia rating } \\
\hline Pneumonia & 73 & 16.2 \\
\hline Severe pneumonia & 368 & 81.4 \\
\hline Very severe pneumonia & II & 2.4 \\
\hline Complicated pneumonia & 102 & 22.6 \\
\hline \multicolumn{3}{|c|}{ Time between onset of symptoms and initial medical treatment (hours) } \\
\hline$<24$ & 57 & 12.6 \\
\hline $24-48$ & 92 & 20.4 \\
\hline $49-72$ & 99 & 21.9 \\
\hline$>72$ & 179 & 39.6 \\
\hline No information & 25 & 5.5 \\
\hline \multicolumn{3}{|l|}{ Signs/symptoms upon hospital admission } \\
\hline Tachypnea & 452 & 100.0 \\
\hline Subcostal retraction & 378 & 83.6 \\
\hline Wheezing & 203 & 44.9 \\
\hline Fever & 126 & 27.9 \\
\hline Grunting & 77 & 17.0 \\
\hline Stridor & 14 & 3.1 \\
\hline Cyanosis & 10 & 2.2 \\
\hline Apnea & 3 & 0.7 \\
\hline $\begin{array}{l}\text { Peripheral saturation measurement }<92 \% \text { or } \\
\text { use of oxygen }\end{array}$ & 233 & 51.5 \\
\hline \multicolumn{3}{|l|}{ Form of oxygen administration } \\
\hline Venturi mask & 113 & 51.6 \\
\hline Nasal catheter & 70 & 32.0 \\
\hline CPAP & 26 & 11.9 \\
\hline Halo & 8 & 3.6 \\
\hline Mechanical ventilation & 2 & 0.9 \\
\hline
\end{tabular}

Abbreviations: CPAP, continuous positive airway pressure; WHO, World Health Organization. range of 6 days, and hospital admissions lasting $\leq 7$ days were more frequent.

Ampicillin was the most used antibiotic (62.2\%) to treat pneumonia, followed by ampicillin associated with gentamicin (7.9\%). Antibiotic therapy was changed during hospitalization in $29.6 \%$ of patients; the main scheme used in these cases was the substitution of ampicillin with oxacillin associated with chloramphenicol.

Table 4 presents the correlation between characteristics and predictors of clinical outcome of pneumonia considering the three classification groups (WHO's severity rating, complicated or uncomplicated pneumonia, and pneumonia with or without hypoxia).

\section{Discussion}

In this study, diagnosis of CAP was based on clinical and radiological criteria established by WHO. Despite criticisms of the WHO criterion for diagnosing pneumonia, we opted to use this classification because it is used in most epidemiological studies. ${ }^{17,18}$ Data collection started 6 months after the introduction of PCV10 in Brazil and continued for 3 years. To the best of our knowledge, no previous studies conducted in Brazil have assessed the clinical profile of pneumonia after this intervention.

With regard to the sociodemographic variables, most children were $<2$ years of age, which is consistent with other studies that indicated low age as a risk factor for pneumonia and highlighted the anatomical peculiarities of the airways and immunological immaturity in this age group..$^{17,18}$ However, because of the large number of nursing children in the study, a group in which viral respiratory infections are frequent ${ }^{19}$ according to WHO criteria of pneumonia, it is difficult to differentiate viral and bacterial pneumonia, and therefore some patients diagnosed with CAP may have had viral infections that were treated as bacterial pneumonia. Blood cultures were requested, but most patients had already 
Table 4 Characteristics and clinical outcome predictors of pneumonia according to the WHO classification of severity according to the presence of complicated and hypoxic pneumonia among hospitalized children aged between I month and 5 years. in Recife, Brazil, 2014

\begin{tabular}{|c|c|c|c|c|c|c|c|c|c|}
\hline & \multicolumn{3}{|c|}{ WHO severity classification } & \multicolumn{3}{|c|}{ Complicated pneumonia } & \multicolumn{3}{|c|}{ Hypoxic pneumonia } \\
\hline & \multirow{2}{*}{$\begin{array}{l}\text { Severe/very } \\
\text { severe } \\
\mathbf{N}(\%)\end{array}$} & \multirow[t]{2}{*}{ Pneumonia } & \multirow[t]{2}{*}{$P$} & \multirow{2}{*}{$\begin{array}{l}\text { Yes } \\
\mathbf{N}(\%)\end{array}$} & No & \multirow[t]{2}{*}{$P$} & Yes & No & \multirow[t]{2}{*}{$P$} \\
\hline & & & & & $\mathbf{N}(\%)$ & & $\mathbf{N}(\%)$ & $\mathbf{N}(\%)$ & \\
\hline \multicolumn{10}{|l|}{ Age } \\
\hline$<$ I year & 157 (83.9) & $30(16.0)$ & 0.94 & II (5.9) & $176(94.1)$ & $<0.01$ & $95(50.8)$ & $92(49.2)$ & 0.46 \\
\hline$\geq$ I year & $222(83.7)$ & $43(12.2)$ & & 91 (33.3) & $174(65.7)$ & & $124(46.8)$ & $|4|(53.2)$ & \\
\hline \multicolumn{10}{|c|}{ Time until initial treatment } \\
\hline$\leq 72$ hours & $208(83.9)$ & $40(16.1)$ & 0.91 & $42(16.9)$ & $206(83.1)$ & $<0.01$ & $125(50.4)$ & $123(49.6)$ & 0.40 \\
\hline$>72$ hours & $150(83.8)$ & $29(16.2)$ & & $54(30.2)$ & $125(69.8)$ & & $82(45.8)$ & $97(54.2)$ & \\
\hline \multicolumn{10}{|c|}{ Length of hospitalization } \\
\hline$\leq 7$ days & $174(76.3)$ & $54(23.7)$ & $<0.01$ & $8(3.5)$ & $220(97.5)$ & $<0.01$ & $88(38.6)$ & $140(6 \mid .4)$ & $<0.01$ \\
\hline$>7$ days & 204 (9l.5) & $19(8.5)$ & & $93(41.7)$ & $130(58.3)$ & & $130(58.3)$ & $93(4 I .7)$ & \\
\hline \multicolumn{10}{|l|}{ Transfer to ICU } \\
\hline Yes & $17(100.00)$ & - & 0.08 & $14(82.3)$ & $3(17.6)$ & $<0.01$ & $16(94.1)$ & I (5.9) & $<0.01$ \\
\hline No & $362(83.2)$ & $73(16.8)$ & & $88(20.2)$ & $347(79.8)$ & & $203(46.7)$ & $232(53.3)$ & \\
\hline \multicolumn{10}{|c|}{ Clinical status after hospitalization } \\
\hline Discharge & $372(83.6)$ & $73(16.4)$ & 0.60 & $99(28.7)$ & $346(7 \mid .3)$ & 0.19 & $214(48.1)$ & $231(51.9)$ & $<0.01$ \\
\hline Number of deaths & $7(100.0)$ & - & & $3(42.8)$ & $4(57.1)$ & & $7(100.0)$ & - & \\
\hline \multicolumn{10}{|l|}{ Pleural effusion } \\
\hline Yes & $110(93.2)$ & $8(6.9)$ & 0.01 & - & - & & 71 (60.2) & $47(39.8)$ & $<0.01$ \\
\hline No & $269(80.5)$ & $65(19.5)$ & & - & - & & I $48(44.3)$ & $186(55.7)$ & \\
\hline \multicolumn{10}{|l|}{ Hypoxia } \\
\hline Yes & $200(91.3)$ & $19(8.7)$ & $<0.01$ & $66(30.1)$ & $153(69.9)$ & $<0.01$ & - & - & \\
\hline No & I 79 (76.82) & $54(23.18)$ & & $36(15.25)$ & 197 (84.75) & & & & \\
\hline
\end{tabular}

Abbreviations: ICU, intensive care unit; WHO, World Health Organization.

made use of antibiotics prior to admission to the IMIP or inclusion at the study and most of them were negative.

Family income $\leq 1$ minimum wage and low maternal education levels reflect the low socioeconomic status of the population studied and are known risk factors for pneumonia. ${ }^{17,18}$ The profile of the study population may have contributed to the delay in seeking medical care, considering that $42 \%$ of the children had their first consultation $>72$ hours after the onset of symptoms. A delay in seeking medical care implies a worse prognosis for $\mathrm{CAP}^{20}$

As observed in Table 2 , only $10 \%$ of the children hospitalized due to pneumonia had low or very low weight for their age according to this ratio. Although the association between malnutrition and infectious diseases is well documented, most of our patients were not malnourished. ${ }^{21}$ This finding can be attributed to socioeconomic changes in Brazil and to improved nutritional indicators. ${ }^{4} \mathrm{~A}$ meta-analysis study indicated that a low weight-for-age was associated with severe lower respiratory infections only in developing countries and that Brazil is undergoing an epidemiological transition. ${ }^{4,22}$

WHO recommends the expansion of the immunization schedule to decrease the incidence of pneumonia in children. ${ }^{23}$
In Brazil, a decreased incidence of pneumonia has been observed in children $<2$ years of age, and in Recife, this decrease reached $28.4 \%$, and the introduction of PCV10 vaccination might actually be one of the best explanations for the decreasing trends in the target age group during the study period. ${ }^{12}$

Despite high vaccination coverage in Brazil, the percentage of children categorized as unvaccinated in the present study deserves attention to correctly interpret the data. PCV10 was universally introduced in 2010 and is administered to children $<2$ years of age. ${ }^{12}$ Because the study sample included children $\leq 5$ years of age and data collection started in October 2010, the percentage of unvaccinated children (50\%) may indicate, in addition to delayed immunization, a fraction of children in this age group that was not included in the Ministry of Health's recommendations. This same observation is valid for the influenza vaccine, which until 2013 was only administered to children between the age of 6 months and 2 years and only during the seasonal period.

Since 1990, WHO has developed and recommended an algorithm for presumptive diagnosis of pneumonia with the aim of reducing morbidity and mortality due to the disease worldwide, particularly in developing countries. ${ }^{5}$ 
Among our patients, the classification of pneumonia included $81.4 \%$ severe cases, $2.4 \%$ very severe cases, and $\sim 16 \%$ of the cases classified as pneumonia. According to WHO and the Brazilian guidelines, $83.8 \%$ of the patients were formally indicated for hospitalization. The fact that $16 \%$ of the patients classified as having nonsevere pneumonia were hospitalized suggests two hypotheses: the WHO severity rating, which is subject to misinterpretation, may have contributed to this decision. or unfavorable social conditions among these children may have justified hospitalization, as recommended by the Brazilian guidelines. ${ }^{5}$

We compared the WHO pneumonia severity rating with two other strategies for categorizing disease severity: presence or absence of complications and presence or absence of hypoxia, as observed in Table 4. It was observed that variables such as length of hospitalization, transfer to the ICU, and death were more frequent among patients with complicated and hypoxic pneumonia compared with those with severe and very severe pneumonia, reinforcing the findings of other studies that indicated the inadequacy of the criteria adopted by WHO for predicting outcomes with worse prognosis. ${ }^{1,7}$

Hypoxia is usually considered a determinant for hospitalization, although it is not included in the WHO criteria or Brazilian guidelines. Despite relatively low cost, pulse oximeters are still inaccessible in some regions. ${ }^{9}$ Previous studies advocate the inclusion of peripheral saturation measurement of hemoglobin as the fifth sign, and we endorse this strategy on the basis of our findings. ${ }^{9,24}$ We recommend its inclusion for the guideline in the initial assessment of the severity of pneumonia. However, further research is required to clarify this issue.

In 2013, WHO issued new guidelines for diagnosing pneumonia in children $<5$ years of age in developing regions. It included only intense subcostal retraction as a diagnostic criterion for severe pneumonia; children with mild subcostal retraction, which formerly indicated severe pneumonia, could now be treated in an outpatient setting. ${ }^{25} \mathrm{WHO}$ recommends that children with subcostal retraction may not be hospitalized, otherwise our results demonstrate that most patients with subcostal retraction needed to remain hospitalized for an average of 4-6 days. This result is an alert and should be taken into consideration, because the new guidelines can decrease the criteria sensitivity in detecting cases of pneumonia that may progress unfavorably.

With regard to defining the diagnosis, we chose to use the clinical diagnosis provided by the pediatrician as well as the radiological evaluation. The results of consolidation and pleural effusion are considered indicative of pneumonia. To define radiologically confirmed pneumonia, we used the WHO recommendations but chose to include the interstitial infiltrate in defining the case. ${ }^{14}$ Although controversial, the WHO proposal has been used in studies that assessed vaccination effectiveness because of its high specificity for bacterial pneumonia. ${ }^{14}$ However, it is not appropriate for clinical purposes. ${ }^{1,6,10,15}$

Despite the well-documented decrease in the incidence of pneumonia, we have observed paradoxically increased severity among hospitalized patients and higher frequency of complications such as pleural effusion. ${ }^{1,8,26}$ The reason for this change remains unknown, but it has been partly attributed to the emergence of more aggressive serotypes of pneumococcus not included in the vaccines. ${ }^{19}$

The frequency of pleural effusion was high in our sample, including patients requiring closed pleural drainage, which accounted for $\sim 60 \%$ of the cases. This result is similar to those of a recent study showing a $27 \%$ rate of pleural effusion among children hospitalized due to pneumonia but differed from the results of older studies, which reported a lower incidence. Another important finding of our study is a higher frequency of complicated pneumonia in children $>2$ years of age, although increased susceptibility has been traditionally described in younger children. This result indicates the need for additional studies to clarify the possible causes. ${ }^{1,26-28}$

Contrary to expectations, considering the greater severity of the disease, the shorter period of hospitalization may indicate more appropriate and effective treatments based on the protocol recommendations.

\section{Conclusion}

In addition to the clinical and epidemiological characterization of pneumonia in children $<5$ years of age, this study permitted the identification of strategies that may contribute to better prognosis. These strategies involve the routine inclusion of $\mathrm{SpO}_{2}$ measurement in diagnosing critically ill patients, education of the population to promote faster access to health care services (primarily initial care), investments in expanded vaccination coverage, better training for health care professionals, and necessity of good hospital infrastructure to care for severely ill patients.

\section{Acknowledgments}

This project was financially supported by Pernambuco Foundation for the Development of Science and Technology (FACEPE), registered under APQ process No 1279-4.01/10. 


\section{Disclosure}

The authors report no conflicts of interest in this work.

\section{References}

1. Chang AB, Ooi MH, Perera D, Grimwood K. Improving the diagnosis, management, and outcomes of children with pneumonia: where are the gaps? Front Pediatr. 2013;1:29.

2. Rudan I. Epidemiology and etiology of childhood pneumonia. Bull World Health Organ. 2008;86(5):408-416.

3. Walker CLF, Rudan I, Liu L, et al. Global burden of childhood pneumonia and diarrhoea. Lancet. 2013;381(9875):1405-1416.

4. Paim J, Travassos C, Almeida C, Bahia L, Macinko J. The Brazilian health system: history, advances, and challenges. Lancet. 2011; 377(9779):1778-1797.

5. Sociedade Brasileira de Pediatria. Diretrizes brasileiras em pneumonia adquirida na comunidade em pediatria - 2007 pneumonias comunitárias. [Brazilian guidelines for community-acquired pneumonia in children - 2007 community-acquired pneumonia]. J Bras Pneumol. 2007;33(1):S31-S50.

6. Lynch T, Bialy L, Kellner JD, et al. A systematic review on the diagnosis of pediatric bacterial pneumonia: when gold is bronze. PLoS One. 2010; 5(8): 11989

7. Nascimento-Carvalho CM, Madhi SA, O'Brien KL. Review of guidelines for evidence-based management for childhood communityacquired pneumonia in under-5 years from developed and developing countries. Pediatr Infect Dis J. 2013;32(11):1281-1282.

8. Bradley JS, Byington CL, Shah SS, et al. Executive summary: the management of community-acquired pneumonia in infants and children older than 3 months of age: clinical practice guidelines by the Pediatric Infectious Diseases Society and the Infectious Diseases Society of America. Clin Infect Dis. 2011;53(7):617-630.

9. Ginsburg AS, Gerth-Guyette E, Mollis B, Gardner M, Chham S. Oxygen and pulse oximetry in childhood pneumonia: surveys of clinicians and student clinicians in Cambodia. Trop Med Int Health. 2014; 19(5):537-544.

10. Iroh Tam P-Y. Approach to common bacterial infections: communityacquired pneumonia. Pediatr Clin North Am. 2013;60(2):437-453.

11. Ribeiro GS, Lima JBT, Reis JN, et al. Haemophilus influenzae meningitis 5 years after introduction of the Haemophilus influenzae type b conjugate vaccine in Brazil. Vaccine. 2007;25:4420-4428.

12. Afonso ET, Minamisava R, Bierrenbach AL, et al. Effect of 10-valent pneumococcal vaccine on pneumonia among children, Brazil. Emerg Infect Dis. 2013;19(4):589-597.

13. BRASIL. Ministério da Saude. Informe Técnico Campanha Nacional de Vacinação Contra a Influenza. [Technical Report National Campaign Against Influenza] Brasilia: Ministério da Saúde; 2014:1-37.

14. World Health Organization Pneumonia Vaccine Trial Investigators' Group. Standardization of Interpretation of Chest Radiographs for the Diagnosis of Pneumonia in Children. Geneva: WHO; 2001:1-30.
15. Xavier-Souza G, Vilas-Boas AL, Fontoura M-SH, et al. The interobserver variation of chest radiograph reading in acute lower respiratory tract infection among children. Pediatr Pulmonol. 2013;48(5): 464-469.

16. Harris M, Clark J, Coote N, et al. Guidelines for the management of community acquired pneumonia in children: update 2011. Thorax. 2011;66(Suppl 2):ii1-ii23.

17. Grant CC, Emery D, Milne T, et al. Risk factors for community-acquired pneumonia in pre-school-aged children. J Paediatr Child Health. 2012; 48(5):402-412.

18. Wonodi CB, Deloria-Knoll M, Feikin DR, et al. Evaluation of risk factors for severe pneumonia in children: the Pneumonia Etiology Research for Child Health study. Clin Infect Dis. 2012;54(Suppl 2): S124-S131.

19. Williams DJ, Shah SS. Community-acquired pneumonia in the conjugate vaccine era. J Pediatric Infect Dis Soc. 2012;1(4):314-328.

20. Rodrigues FE, Tatto RB, Vauchinski L, et al. Pneumonia mortality in Brazilian children younger than or equal to 4 years. $J$ Pediatr (Rio J). 2011;87(2):111-114.

21. Klasen S. Poverty, undernutrition, and child mortality: some interregional puzzles and their implications for research and policy. $J$ Econ Inequal. 2007;6(1):89-115.

22. Jackson S, Mathews KH, Pulanić D, et al. Risk factors for severe acute lower respiratory infections in children - a systematic review and metaanalysis. Croat Med J. 2013;54(2):110-121.

23. Cohen AL, Hyde TB, Verani J, Watkins M. Integrating pneumonia prevention and treatment interventions with immunization services in resource-poor countries. Bull World Health Organ. 2012;90(4): 289-294.

24. Bewick T, Greenwood S, Lim WS. What is the role of pulse oximetry in the assessment of patients with community-acquired pneumonia in primary care? Prim Care Respir J. 2010;19(4):378-382.

25. World Health Organization. Pocket Book of Hospital Care for Children: Guidelines for the Management of Common Childhood Illnesses. 2nd ed. Geneva: WHO; 2013.

26. Calado C, Nunes P, Pereira L, Nunes T, Barreto C, Bandeira T. Are there any differences in the community acquired pneumonias admitted to hospital over the past decade? Rev Port Pneumol. 2010;16(2): 287-305.

27. François P, Desrumaux A, Cans C, Pin I, Pavese P, Labarère J. Prevalence and risk factors of suppurative complications in children with pneumonia. Acta Paediatr. 2010;99(6):861-866.

28. Cardoso MRA, Nascimento-Carvalho CMC, Ferrero F, et al. Empyema and bacteremic pneumococcal pneumonia in children under five years of age. J Bras Pneumol. 2014;40(1):69-72.

29. Loo JD, Conklin L, Fleming-Dutra KE, et al. Systematic review of the effect of pneumococcal conjugate vaccine dosing schedules on prevention of pneumonia. Pediatr Infect Dis J. 2014;33(Suppl 2): S140-S151.
Pediatric Health, Medicine and Therapeutics

\section{Publish your work in this journal}

Pediatric Health, Medicine and Therapeutics is an international, peerreviewed, open access journal publishing original research, reports, editorials, reviews and commentaries. All aspects of health maintenance, preventative measures and disease treatment interventions are addressed within the journal. Practitioners from all disciplines are invited to submit

\section{Dovepress}

their work as well as healthcare researchers and patient support groups. The manuscript management system is completely online and includes a very quick and fair peer-review system. Visit http://www.dovepress.com/ testimonials.php to read real quotes from published authors. 